\title{
High-Resolution Analysis of Ionomer Loss in Catalytic Layers after Operation
}

\author{
T. Morawietz, ${ }^{1}$ M. Handl, ${ }^{1}$ C. Oldani, ${ }^{2}$ P. Gazdzicki, ${ }^{3}$ Jürgen Hunger, ${ }^{4}$ Florian Wilhelm,,${ }^{4}$ \\ John Blake, ${ }^{5}$ K. A. Friedrich, $\oplus^{3,6, *}$ and R. Hiesgen $\oplus^{1, *, z}$ \\ ${ }^{I}$ Department of Basic Science, University of Applied Sciences Esslingen, D-73728 Esslingen, Germany \\ ${ }^{2}$ Solvay Specialty Polymers, R\&D Center, 20021 Bollate (MI), Italy \\ ${ }^{3}$ Institute of Engineering Thermodynamics, German Aerospace Center (DLR), D-70569 Stuttgart, Germany \\ ${ }^{4}$ Zentrum für Sonnenenergie- und Wasserstoff-Forschung Baden-Württemberg, 89081 Ulm, Germany \\ ${ }^{5}$ Johnson Matthey, UTC Swindon, Wiltshire SN1 5ET, United Kingdom \\ ${ }^{6}$ Institute of Energy Storage, University of Stuttgart, 70569 Stuttgart, Germany
}

\begin{abstract}
The function of catalytic layers in fuel cells and electrolyzers depends on the properties of the ionically conductive phase, which are most commonly perfluorinated ionomers based on Nafion and Aquivion. An analysis by atomic force microscopy reveals that the ultrathin ionomer films around $\mathrm{Pt} / \mathrm{C}$ agglomerates have a thickness distribution ranging from $3.5 \mathrm{~nm}$ to $20 \mathrm{~nm}$. Their conductivity and gas permeation properties determine the fuel cell performance to a large extend. For electrodes in Aquivion-based membraneelectrode-assemblies operation-induced structure changes were investigated by means of material- and conductivity-sensitive atomic force microscopy, infrared spectroscopy and electron-dispersive X-ray analysis. The observed thinning of the ultrathin ionomer films was mainly caused by polymer degradation deduced from reduced swelling after long-time operation and a significant loss of ionomer with operation time detected by infrared spectroscopy. From the linear thickness increase of the ultrathin films with rising humidity, a mainly layered structure of the ionomer was deduced. An influence of thickness of such ultrathin ionomer films on fuel cell lifetime was found by analysis of differently prepared membrane-electrode-assemblies, where a linear increase of irreversible degradation rate with ionomer film thickness in the electrodes of unused membrane-electrode-assemblies was found.

(C) The Author(s) 2018. Published by ECS. This is an open access article distributed under the terms of the Creative Commons Attribution Non-Commercial No Derivatives 4.0 License (CC BY-NC-ND, http://creativecommons.org/licenses/by-nc-nd/4.0/), which permits non-commercial reuse, distribution, and reproduction in any medium, provided the original work is not changed in any way and is properly cited. For permission for commercial reuse, please email: oa@ electrochem.org. [DOI: 10.1149/2.0151806jes]
\end{abstract}

(cc) BY-NC-ND

Manuscript submitted December 21, 2017; revised manuscript received February 28, 2018. Published March 15, 2018. This paper is part of the JES Focus Issue on Proton Exchange Membrane Fuel Cell (PEMFC) Durability.

Polymer electrolyte membrane (PEM) fuel cells and also PEM electrolysers are devices for current generation from hydrogen/oxygen and vice versa. Recently, fuel cell power trains were introduced into market by car industry; ${ }^{1}$ PEM electrolyser are foreseen to serve as carbon-free solar and wind energy-powered supply of hydrogen gases at fueling stations. ${ }^{2}$ The membrane-electrode assemblies (MEAs) as main component of a PEM fuel cell and a PEM electrolyser rely mostly on acidic proton exchange membranes with the corresponding ionomer as ionically conducting phase. Generally, proton conductivity does not rely exclusively on an ionomer; it was demonstrated that thin water layers of micrometer length are sufficiently conductive. ${ }^{3-5}$ Even ionomer-free electrodes with excellent properties, the nanostructured thin film (NSTF) catalysts, were realized. ${ }^{6}$ Still, the ionomer in the catalytic layer leads to an improved water management and stability. Recently, major advances have been made to substitute at least partly the costly Pt included as catalyst in the electrodes by Pt alloys or carbon-based materials. In commercial products, platinum still dominates as electrocatalyst, however, Co-Pt alloys have recently been introduced in a commercial fuel cell stack. ${ }^{1}$ Perfluorinated sulfonated ionomers (PFSA) are still advantageous because of their high ionic conductivity and stability under the harsh conditions in electrochemical cells, a prerequisite for a high performance and long lifespan. Both are needed for a successful commercial application. The intended duration of the devices is dependent on the application and ranges from 5,000 $\mathrm{h}$ for fuel cell cars to more than 50,000 $\mathrm{h}$ for busses and electrolysers. ${ }^{2,7,8}$

In such a PFSA ionomer, a phase separation with aggregated polymer backbones and aggregated sulfonic acid-terminated solvated side chains is formed. Commonly used PFSA ionomers are Nafion, a comblike polymer with long sulfonic acid terminated side chains (long side chain LSC) and Aquivion with shorter side chains (SSC). To a large

\footnotetext{
*Electrochemical Society Member.
}

${ }^{\mathrm{z}}$ E-mail: renate.hiesgen@hs-esslingen.de extent, the performance of fuel cells and electrolysers depends on a high proton conductivity of the ionomer, which is determined by its detailed ionomer nanostructure, i.e. size of the phases, and on the water content of its hydrophilic phase. For current flow, a continuous proton conductive network is needed. It requires a connection of the hydrophilic phase throughout the ionomer and contacts to both catalytically active electrodes. According to the modeling of Kreuer and Borges and atomic force microscopy (AFM) measurements on fresh ionomer membrane cross-sections, ${ }^{9-13}$ large areas of the polymer have a lamellar structure with water enclosed as layers of varying thickness. Numerous experimental and modelling work has been performed to determine the detailed structure of PFSA, most experiments were performed with Nafion. ${ }^{14,15}$ One hurdle is that the PFSA nanostructure is not stationary but adapts according to its history in use and conditions, i.e., humidity changes, temperature, pressure, and current flow. ${ }^{16}$ It has been observed that a continuous ionically conductive network forms upon forced current flow at first voltage application. ${ }^{11}$ Due to its visco-elastic properties also its structure permanently changes upon environmental variations and an equilibrium structure is rarely reached..$^{17}$ To get insight into the relevant ionomer nanostructure and its subsequent properties for a certain application, an investigation under non-equilibrium conditions close to this application is needed.

Electrode structure.-The electrodes are key components of the fuel cells. They typically consist of ionomer, $\mathrm{Pt}$, and mesoporous carbon. By means of material-sensitive AFM, ${ }^{17}$ the different components can be discerned by a high contrast in adhesion force, stiffness, and deformation. ${ }^{13}$ AFM also provides a large contrast in adhesion (pull-off) force and stiffness mappings between the water-rich hydrophilic and the hydrophobic phases of an ionomer, and can detect water-rich areas by their higher conductivity. ${ }^{18}$ In contrast to electron beam based techniques, ${ }^{19}$ where the samples are imaged in vacuum with significant polymer shrinkage due to the dry environment, AFM works in humid environment and liquid. Humidity and temperature 
can be chosen to be most relevant for the intended operation, i.e. under humid conditions for fuel cell application or under water for electrolyser application. Furthermore, no beam intensity damages need to be considered like in electron microscopies.

Degradation analysis.-Degradation of ionomer within the MEA can affect the ionomer membrane and the electrodes and is induced by mechanical and chemical means. Numerous publications deal with the different aspects of degradation and their mitigation. ${ }^{20-29}$ For ionomer degradation, two main routes are known, chemical and mechanical degradation. Both can lead to a loss of performance or even a total failure of a cell. For chemical degradation in fuel cells, promoting factors are low relative humidity, high temperature, and high cell voltage. For mechanical degradation, mainly humidity cycling and damage during MEA fabrication contribute to degradation.

Chemical degradation is caused by the formation of radicals. For chemical attack of polymer via peroxide formation, $\mathrm{H}_{2}$ and $\mathrm{O}_{2}$ reactions in combination with cation contamination, for example $\mathrm{Fe}$-ions that are the basis of the Fenton's reaction used as accelerated degradation test, ${ }^{30}$ play a major role. Radical attack can lead to ionomer side chain unzipping with loss of sulfonic acid groups and attack of the main polymer chain. In this case polymer degradation occurs with release of fluoride. Known consequences are a thinning of the ionomer membrane that leads to increased gas permeation rates, pin-holes and crack formation. ${ }^{8}$ Membrane thinning increases the hydrogen crossover through the membrane. Mixing of oxygen and hydrogen gas reduces the cell potential and a reaction of those two gases releases a large reaction heat. ${ }^{8}$ In addition, when hydrogen gas reaches the anode side in the presence of oxygen, another degradation pathway occurs at the anode. In the presence of hydrogen, peroxide radicals can form hydrogen radicals that strongly attack the ionomer and further increase degradation, i.e. in fuel cells anodes as described by Coms..$^{20,31}$ The implementation of thinner membranes that provide a lower resistance with higher cell performance also increases gas permeation and therefore leads to a higher degradation risk.

For stabilization of membranes radical scavengers are nowadays introduced in the membranes and can prolong their life-time significantly. ${ }^{32-34}$ In the electrodes of this study no radical scavenger were used. Although, the degradation of the ionomer not only affects the membrane, but also the electrodes. Electrodes are a porous composite of platinum catalyst particles supported on mesoporous carbons mixed with ionomer. The catalyst layer properties have to be optimized to achieve high utilization of the catalyst material and superior performance. Important properties are reactant diffusivity, ionic and electrical conductivity, and the level of hydrophobicity. In this respect ionomer structure is important as it also determines the resiliency of the catalyst. Different analysis methods were used for detection of ionomer size in electrodes. ${ }^{19,35,36}$ In catalytic layers of fuel cells an operation-induced thinning of the ionomer films that partly encapsulate the platinum covered carbon $(\mathrm{Pt} / \mathrm{C})$ agglomerates has been reported. ${ }^{13,37,38}$ The observed stronger thinning of the ionomer layers in the anode at samples cut close to the hydrogen inlet and with the use of thin membranes was explained by the higher concentration of highly active hydrogen radicals. ${ }^{20}$ Since the thickness of the ionomer layers within electrodes ranges from roughly $4 \mathrm{~nm}$ to $20 \mathrm{~nm}$, the conductive properties as well as the gas permeation are affected by the properties of such nanothin films. It is known that their properties differ significantly from those of bulk ionomer layers $(>50 \mathrm{~nm})^{39-45}$ and consequently affect the macroscopic properties of fuel cell electrodes. Differences include structure, ${ }^{10}$ surface energy, ${ }^{46}$ and conductivity. ${ }^{15,46}$ Borges et al. reported on modeling of the structure of ultrathin Nafion films on substrates with different surface energy. ${ }^{47,48}$ On hydrophilic surfaces for films with a thickness of $4.5 \mathrm{~nm}$, a water layer is present at the substrate covered by a polymer layer, on hydrophobic substrates a water layer is enclosed within two polymer layers. For thicker films and low water content, the formation of inverted micelles and multilayers becomes more favorable. Paul et al. reported that self-assembled films of Nafion from alcoholic dispersion resulted in a minimum film thickness of $4 \mathrm{~nm}$ on $\mathrm{Si}$ and

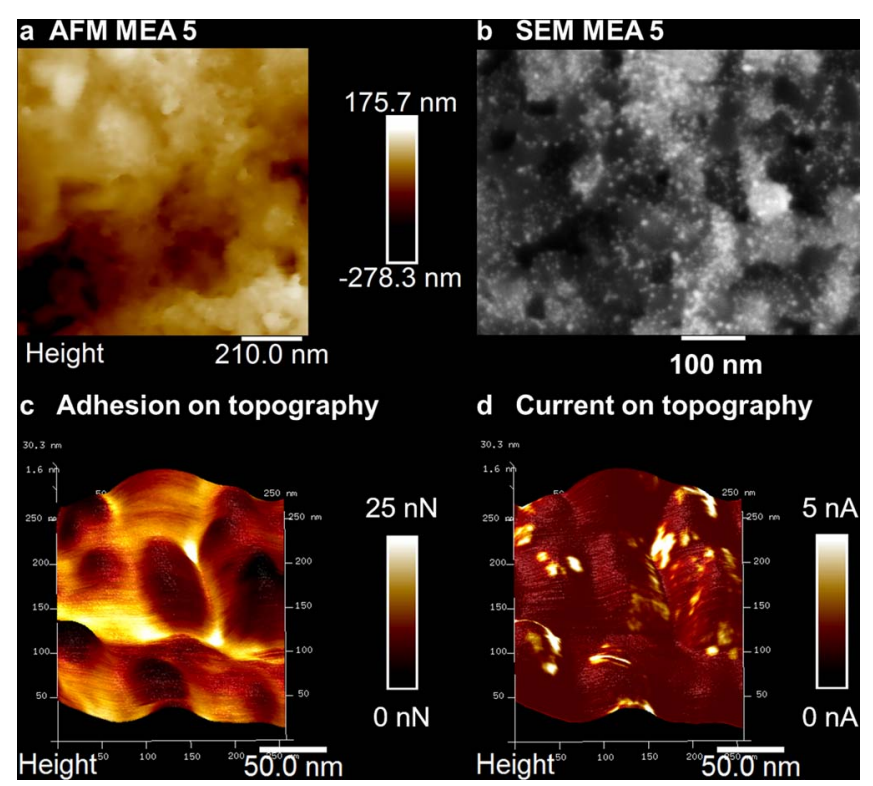

Figure 1. MEA5 cross-sectional images of electrode: (a) AFM, (b) SEM, (c) AFM adhesion mapping on topography, and (d) AFM measured current overlaid on topography.

sputtered Pt films on Si. These films exhibited a layered structure and had a hydrophilic surface in contrast to thicker films $(>50 \mathrm{~nm})$, which were hydrophobic. $^{40,42,43}$ In contrast to the first publications, recently no difference was found for water-uptake of ultrathin films, and the claimed difference in conductivity could not be confirmed. ${ }^{46}$ To our knowledge on such properties of nanothin Aquivion films only one report has been published. ${ }^{49}$

During operation, chemical attack of ionomer can be analyzed in-situ by determination of F-emission rates or indirectly by following changes during operation by electrochemical analysis, i.e. cyclic voltammetry, current-voltage curves, and impedance analysis. Post mortem analysis of electrodes was performed in a variety of methods, including different microscopy methods, scanning electron microscopy, ${ }^{37,50}$ transmission electron microscopy, ${ }^{51-55}$ AFM $;{ }^{56,57}$ spectroscopic techniques such as infrared spectroscopy (IR, attenuated total reflection (ATR)), $\mathrm{X}$-ray spectroscopy (XPS, scanning transmission X-ray microscopy $($ STXM) $),{ }^{52,54,58-62}$ neutron reflectivity, ${ }^{63}$ and other experiments such as water sorption, ${ }^{64}$ BET-analysis (surface determination invented by S. Brunauer, P. H. Emmett, E. Teller), differential scanning calorimetry, ${ }^{65}$ at electrode surfaces or MEA cross-sections. ${ }^{50,66,67}$

In this study we performed post-test analysis on cross-sections of fuel cell electrodes. Beside a Nafion-based commercial reference MEA purchased from Johnson Matthey (Swindon, UK), the MEAs were prepared with Aquivion PFSA as ionomer for the electrodes and as membrane. They were developed in the framework of the European project "IMPACT", dedicated to reduction of platinum content. The dependence on operation time of electrode structure, conductivity, ionomer distribution, and thickness distribution of ionomer films, which cover the $\mathrm{Pt} / \mathrm{C}$ agglomerates of differently prepared electrodes, was investigated by means of mainly material-sensitive AFM, IR, and energy-dispersive X-ray analysis (EDX). Depending on preparation and operation, a significant thinning of the ionomer films that cover the $\mathrm{Pt} / \mathrm{C}$ agglomerates in the electrodes was observed. ${ }^{13}$ In the SEM, the ionomer in the electrode is hardly visible due to significant shrinkage in the dry vacuum environment; also the contrast between ionomer and carbon is weak. AFM was therefore used as main method, because it works at elevated humidity and provides a large contrast between ionomer and $\mathrm{Pt} / \mathrm{C}$ components. In Figure 1, AFM (Figure 1a) and SEM (Figure 1b) images of the same electrode of MEA 5 are shown. The high-resolution current 
Table I. Summary of analyzed test objects. The MEAs marked bold have been investigated in detail; the others are included as further data in Figure 11.

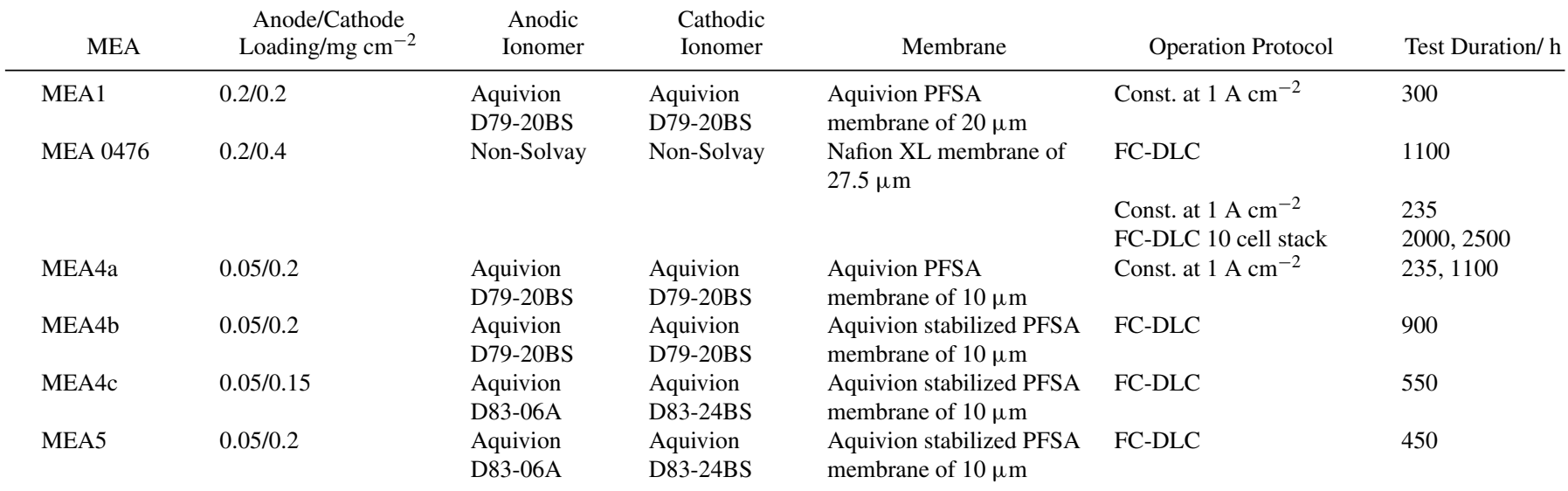

image (Figure 1d) indicates ionomer-free carbon particles with exposed Pt surface, which appear darker in the adhesion images are conductive; in contrast the carbon particles covered by ionomer (bright in adhesion mapping, i.e. top of Figure 1c) are not conductive.

In this study the degradation-induced changes of ionomer film distribution within fuel cell catalytic layers were analyzed using AFM at constant high relative humidity. The possible reasons for the ionomer thinning in the electrodes are discussed and compared with experimental evidence.

\section{Experimental}

MEAs. - The Pt/C based MEAs tested in the frame of this work were developed within the European project "IMPACT". The project goal was the development of a low-loaded $\left(0.2 \mathrm{mg} / \mathrm{cm}^{2}\right)$ Aquivionbased MEA with a lifetime of 5,000 hours dynamic operation in stack, and (ii) single cell performances of $1 \mathrm{~W} / \mathrm{cm}^{2}$ at $670 \mathrm{mV}$ cell voltage.

In Table I the disclosed MEA specifications are provided. All MEAs were catalyst-coated membranes. The catalyst and the carbon in the electrodes were non-commercial. The Aquivion membrane from Solvay Speciality Polymers (Bollate, Italy) was combined with ionomer dispersions in the electrodes from the same source. As visible in Table I, with the exception of MEA 1 with a $20 \mu$ m-thick membrane, always a $10 \mu \mathrm{m}$-thick reinforced membrane was used; the ionomer grades, catalysts and preparation were changed according to the results of single cell measurements. As a commercial reference, a Nafion-based MEA 0476 (reinforced Nafion XL membrane of $27.5 \mu \mathrm{m}$ thickness with an anode Pt loading of $0.2 \mathrm{mg} \cdot \mathrm{cm}^{-2}$ and a cathode loading of $0.4 \mathrm{mg} \cdot \mathrm{cm}^{-2}$, purchased from Johnson Matthey (Swindon, UK) was used. Different, not disclosed preparation methods were used for MEA fabrication. Beside the information summarized in Table I, no further details on the electrode materials and preparation methods are available.

The samples of experimental MEA $4 \mathrm{c}$ and the commercial MEA were cut from $\mathrm{H}_{2}$-inlet, the samples of experimental MEA 4a, MEA $4 \mathrm{~b}$, and MEA 5 were cut from the center. Italy:

Ionomer dispersions from Solvay Specialty Polymers, Bollate,

Aquivion D79-20BS, water-based, equivalent weight (EW) $790 \mathrm{~g} / \mathrm{mol}$

Aquivion D83-06A, hydroalcoholic, EW $830 \mathrm{~g} / \mathrm{mol}$

Aquivion D83-24BS, water-based, EW $830 \mathrm{~g} / \mathrm{mol}$

Stabilized membranes: including radical scavengers

Operation conditions._-During the MEA development, the MEAs were tested in single cells, all operated by DLR. With one exception, only these samples were used for AFM post-mortem analysis. The commercial reference MEA and the thoroughly analyzed MEA 4a were operated in $25 \mathrm{~cm}^{2}$ cells at constant current of $1 \mathrm{~A} / \mathrm{cm}^{2}$. The MEAs $4 \mathrm{~b}, 4 \mathrm{c}$, and 5 were operated under dynamic operation using the Fuel Cell Dynamic Load Cycle (FC-DLC) developed in the FCH JU Stack-test project (Figure 2b) ${ }^{68,69}$ The tests consisted of several test blocks each divided into an operation period and a recovery period to discriminate between reversible and irreversible degradation as shown in Figure 2a. Since operation in a stack may lead to other degradation mechanism, selected MEAs were tested in a long-time stack operation in a $100 \mathrm{~cm}^{2}$ scale at ZSW, Ulm. In Figure $8 \mathrm{~b}$, two measurements of samples from the commercial reference MEA, after 2000 and $2500 \mathrm{~h}$ of operation time in a stack, were included to show the course of long-time electrode degradation. Detailed information on the testing of single cells are provided in Gazdzicki et al. ${ }^{70}$ The stack operation also followed the Fuel Cell Dynamic Load Cycle (FC-DLC) with same operating conditions except a larger active cell area of $100 \mathrm{~cm}^{2}, \mathrm{Z}$ shaped serpentines on bipolar plates, an operation in counter-flow with $\lambda_{\text {Anode }}=1.5, \lambda_{\text {Cathode }}=2.0$ near atmospheric pressure up to 2 bar $_{\mathrm{g}}$, and an anode and cathode pressure of max. 3.0 bar $_{\text {abs }}\left(0.1-2.0 \mathrm{bar}_{\mathrm{g}}\right)$. The operation protocols for each tested MEA are summarized in Table I. As gas diffusion layers, on both electrodes always SIGRACET GDL 25 BC 'DECODE' (SGL CARBON GmbH, Meitingen, Germany) with enhanced hydrophobicity were used.

AFM.-AFM measurements were performed using a Multimode 8 AFM in tapping mode purchased from Bruker, Karlsruhe. For mapping of material properties, the PeakForce QNM-mode and for current sensing the TUNA-module were used. For averaging the current retrieved in tapping mode, which contains steady-state and transient current contributions, different time constants can be chosen for averaging the current signal with the built-in lock-in amplifier. With PeakForce QNM-mode, mapping of local height, adhesion, stiffness (DMT modulus, stiffness proposed by Derjagin, Muller, Toropov in 1975), deformation, and dissipation was performed. ${ }^{12,17,18}$ Atomic force microscopy takes advantage of the higher contrast in adhesion (pulloff) force and stiffness between the ionomer and the carbon/platinum components. ${ }^{13}$ The local ionic current at constant relative humidity in a gastight chamber was recorded using a platinum coated catalytically active tip. The fraction of non-conductive/conductive area was retrieved from area analysis of the images. More details on the AFM measurements can be found in Hiesgen et al. ${ }^{12,17,18,71}$ For AFM analysis of MEAs, freshly prepared cross-sections were imaged. The cross-sections were cut by microtome after embedding the MEA into 2-component polyurethane (Teromix, BASF) for stabilization. Prior to AFM measurements, the cross-sections foreseen for AFM analysis were equilibrated for 2 weeks in a gastight chamber at the intended relative humidity. For control of humidity the samples were stored in a sealed box together with a humidity control unit (Cigar Oasis 


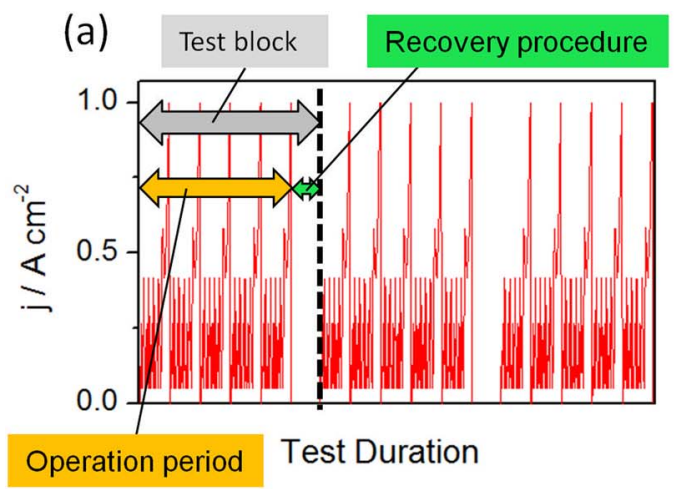

(b)

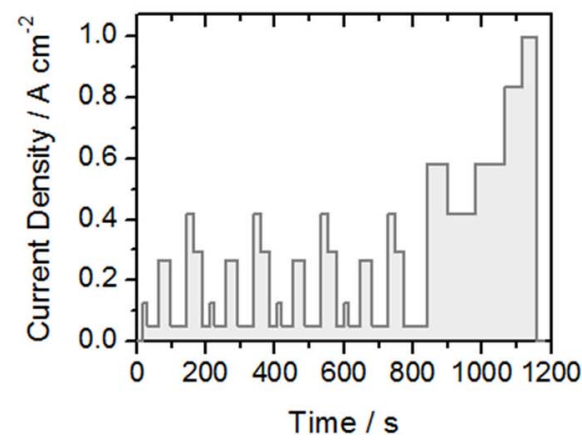

Figure 2. (a) Scheme of a typical durability test, and (b) a single cycle of the FC-DLC protocol.

Ultra, Cigar Oasis, Farmingdale, NY, USA). The sufficient equilibration time had been determined separately.

The determination of ionomer films in the electrodes was performed as reported in Morawietz et al. ${ }^{13}$ After 2 weeks of equilibration of the embedded MEA at constant humidity, fresh electrode crosssections were prepared by microtome-cutting. The resulting samples were fixed on the metallic sample holder disc using double-sided adhesive conducive tape. With material-sensitive AFM analysis, a high contrast between ionomer phase und $\mathrm{Pt} / \mathrm{C}$ components is present in adhesion force, deformation, stiffness, and conductivity. The ionomer layer thickness distribution was derived from analysis of adhesion force images, measured with an AFM tip (SHR150, 5 Nm-1, Budgetsensors) of less than $1 \mathrm{~nm}$ nominal radius and a pixel size of $<1 \mathrm{~nm}$, for high-resolution images of $<0.36 \mathrm{~nm}$. For control of humidity, the AFM head was operated in a gas -tight chamber equipped with a humidity control unit (Cigar Oasis Ultra, Cigar Oasis, Farmingdale, NY, USA). As measure for the layer thickness, the distance between the turning points of the adhesion force profile was measured. Care was taken, that layers were evaluated at reasonable flat areas to avoid the inclusion of imaging artefacts. As a single meaningful thickness of an electrode, the position of the peak in the resulting histogram, derived from a log-normal plot, was used.

Infrared spectroscopy.-Changes in polymer composition can be detected by IR spectroscopy. The amplitude decrease of $\mathrm{SO}_{3}{ }^{-}$related frequencies indicates the loss of sulfonic acid groups and therefore, for PFSA a loss of sulfonic acid group terminated side chains. After careful removal of the gas diffusion layers, IR was performed in the range 4000 to $800 \mathrm{~cm}^{-1}$ using a Bruker Alpha IR spectrometer in surface-sensitive attenuated total reflection (ATR)-mode with the window placed on top of the electrodes. After correction of the baseline, the peaks were integrated using the OPUS software. Due to the high absorption of carbon and platinum, the C-O-C and $\mathrm{SO}_{3} \mathrm{H}$ peaks were analyzed together $\left(970-1060 \mathrm{~cm}^{-1}\right)$. An average over 10 measurements was calculated together with a standard error of the mean for a confidence level of $68 \%$.

$\boldsymbol{E D X}$.-EDX analysis of the electrodes was performed by an Oxford detector mounted in a Zeiss LEO 455VP scanning electron microscope. For detection of the $\mathrm{SO}_{3} \mathrm{H}$-content, prior to analysis the protons were exchanged to $\mathrm{K}$ ions, which were detected by EDX analysis. For proton exchange, the MEAs were stored in a $1 \mathrm{~mol} \cdot \mathrm{l}^{-1}$ $\mathrm{KOH}$ solution for $24 \mathrm{~h}$, rinsed with ultrapure water, and after drying analyzed with EDX at different areas. A mean value and the standard deviation of the mean were calculated. For the EDX analysis of electrode cross-sections MEAs samples were freeze-fractioned. During analysis penetration of electrons into the membrane ionomer was avoided.

\section{Results and Discussion}

MEA.-In Figure 3, AFM images of a cross-section of the pristine MEA 5 are given with topography (Figure 3a), corresponding stiffness (Figure 3b), and current mapping (Figure 3c). In the topography image, the electrodes and the reinforced ionomer membrane differ by their height; the stiffness mapping reveals a high stiffness for the platinum containing electrodes (bright area) at both sides. As visible in Figure 3, the reinforcement within the membrane is not centered within the ionomer, which leads to significant narrowing and even vanishing of the adjacent ionomer layer. This frequently observed inhomogeneity is caused by the manufacturing of the only $10 \mu \mathrm{m}$-thick membrane.

The lowest stiffness is visible for the ionomer layers that enclose the reinforcement in the center. At a bias voltage of $15 \mathrm{mV}$, only the electronic current at the electrodes was detected with a grainy appearance that reflects the multi-component electrode composition.

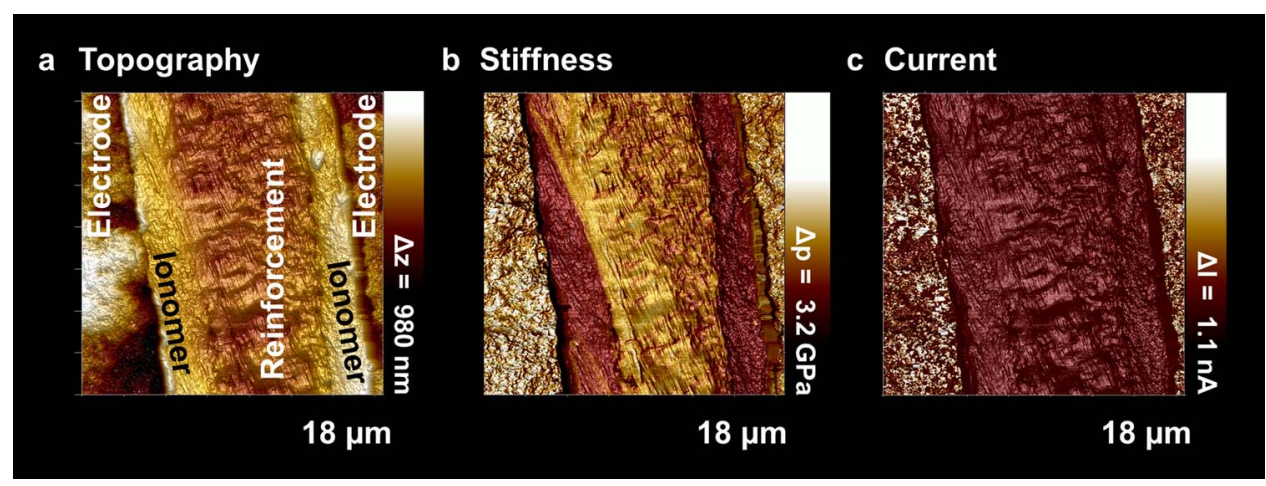

Figure 3. AFM measured mappings of cross-sections of MEA 5, measured at 55\% RH, (a) topography, (b) stiffness (DMT modulus), and (c) electronic current at $15 \mathrm{mV}$. 


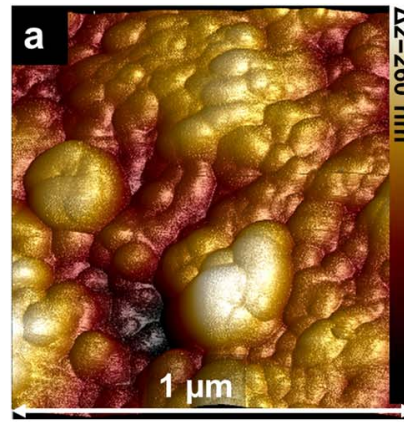

Topography

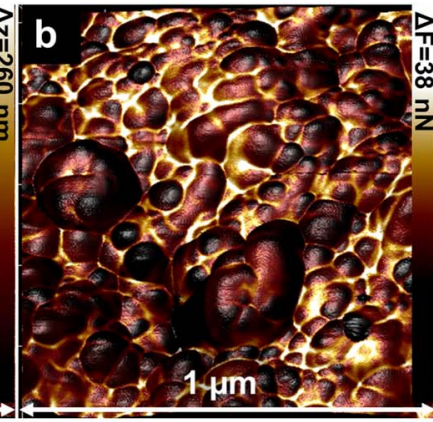

Adhesion on topography

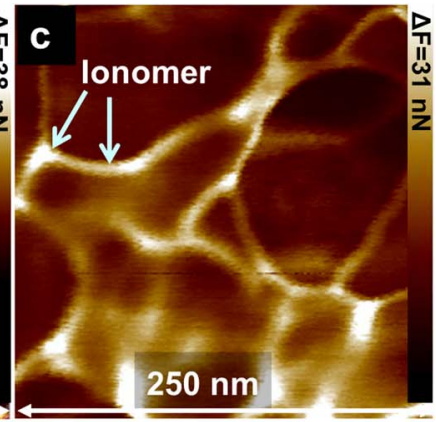

Adhesion

Figure 4. AFM images of the pristine cathode of MEA 4b, measured at 60\% RH, (a) topography, (b) corresponding adhesion image, and (c) high-resolution adhesion force mapping with bright ionomer films marked by arrows.

Electrode structure.-An example of the AFM-measured electrode structure at cross-section is given in Figure 4 with topography (Figure 4a), corresponding adhesion mapping (Figure 4b), and a close-up zoomed adhesion image of the electrode nanostructure in Figure 4c. The topography image exhibits elevated Pt/C agglomerates. In the adhesion image in Figure $4 \mathrm{~b}$, the ionomer appears as bright phase and Pt-coated carbon as black areas on the brown carbon agglomerates. Areas with more ionomer appear swollen in the topography mapping of Figure $4 \mathrm{a}$. In the high-resolution adhesion image in Figure $4 \mathrm{c}$, the thin ionomer films around the $\mathrm{Pt} / \mathrm{C}$ agglomerates are marked by arrows. A few bright ionomer clusters can also be observed. The porosity is not easily visible in AFM height images because the tip follows the curvature of pore. An estimation of the porosity can be determined by evaluation of the solid area on subsequent planes cutting parallel through the surface and subsequent integration of the free volume. For the electrode in Figure 4, a porosity of $45 \%$ has been evaluated.

Influence of fuel cell operation.-Thinning of ionomer films.The distribution of ionomer film thicknesses in electrodes measured by AFM resulted in a histogram with a typical spread of the ionomer film size ranging from minimal $3.5 \mathrm{~nm}$ (Aquivion) and $4.5 \mathrm{~nm}$ (Nafion) up to $15-20 \mathrm{~nm}$. In Figure 5a, the thickness distribution is shown for an anode cross-section of MEA 4a before fuel cell operation and after $1100 \mathrm{~h}$, analyzed with AFM at a relative humidity (RH) of $60 \%$. The average ionomer film thicknesses retrieved from a log-normal fit to the data were determined to $7.0 \mathrm{~nm}$ before and $5.3 \mathrm{~nm}$ after $1100 \mathrm{~h}$ of operation. After fuel cell operation, a thickness decrease of more than $1 \mathrm{~nm}$ occurred. In Figures 5b, the operation time-dependent average thickness is depicted for the anode and the cathode. After a small increase of film thickness after $235 \mathrm{~h}$ of operation due to water uptake through operation and additional humidification by current flow, a
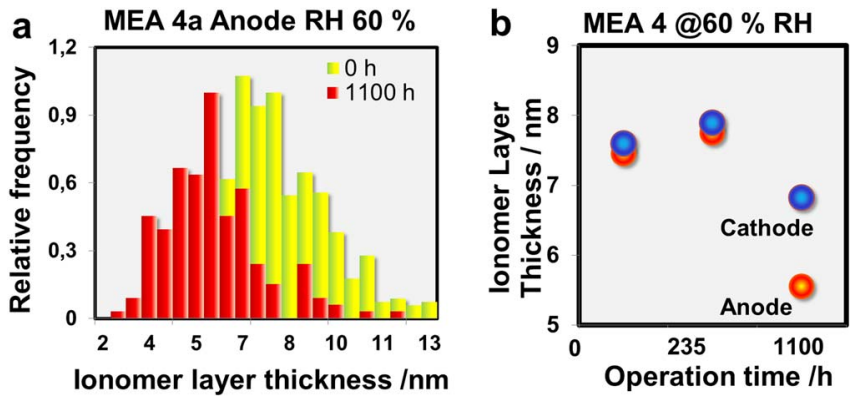

Figure 5. (a) Distribution of ionomer film thickness of pristine and $1100 \mathrm{~h}$ operated anodes of MEA 4a, measured with AFM at $60 \% \mathrm{RH}$, (b) dependence of average ionomer film thickness on operation time of anode and cathode of MEA 4a. The MEAs were tested in a single cell under static conditions at DLR, Stuttgart. more significant thickness decrease is visible after $1100 \mathrm{~h}$. A more pronounced thinning of the anode ionomer films was found for this sample which was cut close to the hydrogen inlet, similar to the results reported in. ${ }^{13}$

Factors that can lead to a thinning of the ionomer films in the catalytic layers include

(i) Degradation of ionomer by radical attack of side chains with loss of sulfonic acid groups. As a result, a decrease of $\mathrm{SO}_{3} \mathrm{H}-$ related IR-signal $\left(970-1060 \mathrm{~cm}^{-1}\right)$, less swelling of the ionomer films after operation and a decrease of the total nonconductive area are expected.

(ii) Pressure/temperature induced flow of ionomer during operation, i.e. to pores within the electrode. In this case ionomer redistribution in the catalytic layer may occur, but the total ionomer area detected at the electrode cross-section would stay nearly constant. Furthermore, without ionomer degradation, no difference in ionomer film swelling before and after operation is expected.

(iii) A restructuring of the ionomer films with a transformation from ionomer clusters/micelles to layers. In this case the number of ionomer clusters would decrease with operation time.

Also a combination of these factors could contribute to the resulting ionomer film thinning. These different reasons will be discussed in the following sections.

Swelling of ionomer films. - The total ionomer area in the electrodes comprises two fractions, the thin ionomer films that cover the $\mathrm{Pt} / \mathrm{C}$ agglomerates and the bigger ionomer agglomerates that account significantly to the total amount of ionomer. The amount of sulfonic acid groups determines the water uptake and swelling of the ionomer. Therefore, a reduced swelling of the thin ionomer films around $\mathrm{Pt} / \mathrm{C}$ agglomerates with humidity increase indicates a loss of sulfonic acid groups caused by ionomer degradation. The change of average film thickness on humidity is given in Figures $6 \mathrm{a}, 6 \mathrm{~b}$. The anode and cathode samples of MEA 4a (Aquivion D79-20BS, MEA center, $10 \mu \mathrm{m}$ thick membrane) were equilibrated for 2 weeks at controlled humidity and measured at the same RH by AFM. The swelling is expressed by the slope of the dependence of thickness on humidity and is a measure for the amount of sulfonic acid groups in the ionomer. In the anode (Figure 6a), the swelling of the ionomer films of the pristine sample and of that operated for $235 \mathrm{~h}$ are similar and no decrease of total ionomer film thickness occurred. In the cathode (Figure 6b), after $235 \mathrm{~h}$ of operation a decrease of the absolute ionomer film thickness of roughly $1 \mathrm{~nm}$ compared to the pristine cathode is visible. Here, the swelling of the ionomer films seems to be even stronger than for the pristine sample, an effect that is likely related to enhanced humidification through the higher platinum content in the cathode. ${ }^{72} \mathrm{~A}$ detectable loss of sulfonic acid groups occurred (see below), but did not dominate the swelling behavior. 

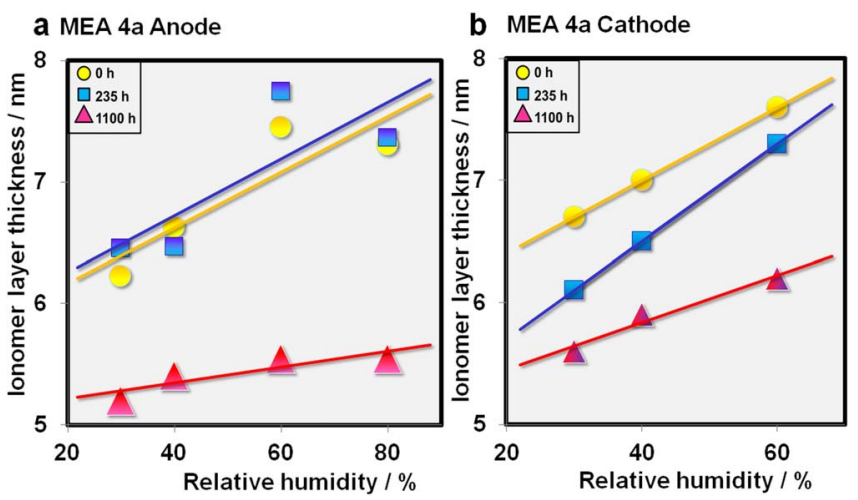

Figure 6. Dependence of ionomer (Aquivion D79-20BS) film thickness on relative humidity and operation time, for (a) anode, and (b) cathode of MEA 4a. The MEAs were tested in a single cell under static conditions at DLR, Stuttgart.

After $1100 \mathrm{~h}$ of operation, in the anode a large ionomer film thinning and negligible swelling can be observed that indicates a significant decrease of sulfonic acid groups and in conclusion ionomer degradation. In the cathode, also a large thinning occurred. The swelling of the ionomer films with humidity increase is slightly reduced compared to the pristine cathode, but higher than at the anode. A small loss of sulfonic acid groups can be deduced, but an additional ionomer flow must have happened. The humidity dependence of the ionomer film thicknesses confirms degradation of the ionomer films, higher at the anode than at the cathode. The swelling of the Aquivion films always follows a linear slope (Figure 6). Such a linear swelling has also been reported in early publications on Nafion and is expected for an ionomer structure dominated by layers. The favored formation of such ultrathin films as layers has also been reported recently by Borges et al., who performed structure simulations of Nafion. ${ }^{10,14,73,74}$ Berrod et al. reported a pronounced lamellar structure with enclosed water layers of confined PFSA (Nafion and Aquivion), derived from combined small-angle X-ray scattering, quasielastic neutron scattering, and pulsed-field gradient NMR measurements. They demonstrated a linear swelling of the layers with increasing water fraction at medium humidity as used in this study. ${ }^{75}$ In case of hydrophilic substrates such as platinum covered carbon, a water film is present at the $\mathrm{Pt} / \mathrm{C}$ surface, covered by the ionomer chains. The ionic conductivity is provided by the water film. The proton current is flowing predominantly along the surface covered by catalyst particles. The current flow can be interrupted by free pores space or missing ionomer, i.e. at Pt-free hydrophobic carbon surface. Recently, Eikerling et al. reported a significantly enhanced proton concentration for pore geometries for which the total Debye length is greater than the pore width that further enhances conductivity. ${ }^{76}$ In addition, the thickness and structure of the ionomer influences the oxygen permeation to the catalyst particles. ${ }^{77}$ A reduction in Pt loading of the electrodes could decrease the fraction of hydrophilic surface area ${ }^{78}$ and may influence the resulting ionomer structure and the electrode conductivity.

Infrared spectroscopy.-The intensity of the infrared spectroscopy signal is related to the amount of $\mathrm{SO}_{3} \mathrm{H}$-groups and is a measure for the amount of sulfonic acid groups and therefore the ionomer. A decrease of the specific IR intensity indicates a loss of $\mathrm{SO}_{3} \mathrm{H}$-groups and loss of ionomer. In Figure $7 \mathrm{a}$, the decrease of the $\mathrm{SO}_{3} \mathrm{H}$-group-related relative IR intensity with operation time, derived from the specific peak area is shown for two different MEAs. In Figure 7a, the IR intensity is given for the electrodes of the experimental Aquivion-based MEA 4a with a membrane thickness of $10 \mu \mathrm{m}$, cut from the MEA center, and in Figure $7 \mathrm{~b}$ for the commercial Nafionbased MEA 0476 with a membrane thickness of $27.5 \mu \mathrm{m}$, cut from the MEA hydrogen inlet. In this case, the peak area related to $\mathrm{SO}_{3} \mathrm{H}$ groups is normalized to the area of $\mathrm{CF}_{2}$ groups, to demonstrate a preferred loss of sulfonic acid groups compared to polymer main chain degradation. In Figure $7 b$, data points after short static and longer dynamic operation times are plotted for the Nafion-based commercial MEA 0476. In any case, a decrease of IR intensity and therefore a decrease of ionomer with operation time is visible. At the cathode of MEA 0476 only a slight decrease of IR intensity occurred after $2500 \mathrm{~h}$ of operation, whereas at the anode a clear decrease to half of the initial signal indicates a preferential decrease of sulfonic acid groups. After $1100 \mathrm{~h}$ of static operation of the Aquivion-based sample cut from MEA 4a center (Figure 7a), the IR intensity has decreased to more than half for both electrodes. In conclusion, significant ionomer degradation at both electrodes had occurred. The difference in ionomer degradation between MEA 0476 and MEA 4a is similar to previous measurements. ${ }^{13}$ It can be explained by similar reasons, the different sample positions within the MEA (hydrogen inlet and center) account for different degradation rates that are related to more hydrogen radicals present at the anode close to the hydrogen inlet. ${ }^{20}$ In addition, the differences in membrane thickness $(27.5 \mu \mathrm{m}$ and $10 \mu \mathrm{m})$ may also lead to differences in hydrogen permeation and thereby to different degradation rates, higher for thinner membranes. ${ }^{13}$

Non-conductive area.-As a further indication of ionomer loss, the development of non-electronically conductive area can be examined. The evaluation of the non-conductive area with operation time evaluated from AFM current mappings of $3 \times 3 \mu \mathrm{m}^{2}$, measured at electrode cross-sections of both MEA 4a electrodes is given in Figure 7c. The fraction of non-conductive area decreased for both electrodes. A decrease of non-conductive area, derived from the electronically a

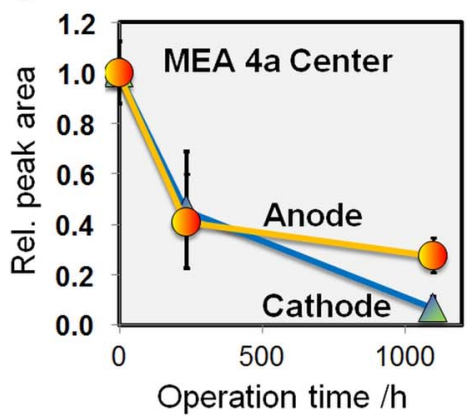

b

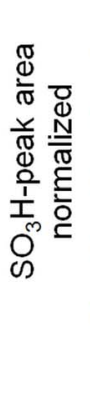

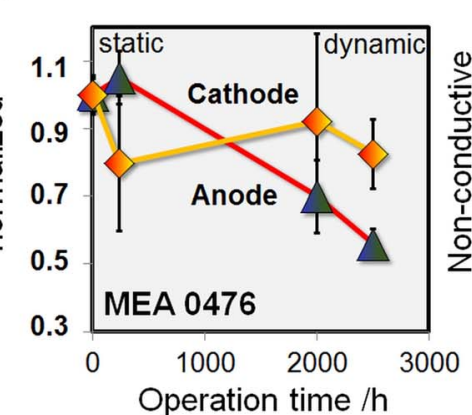

C

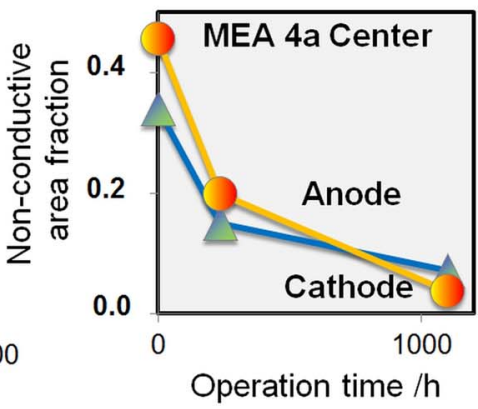

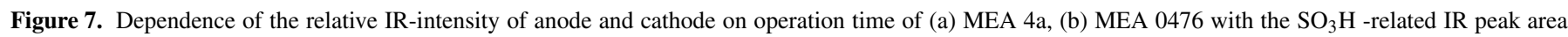

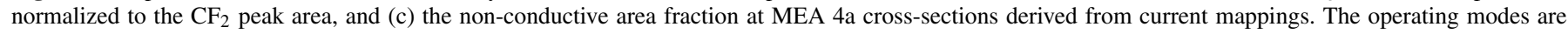

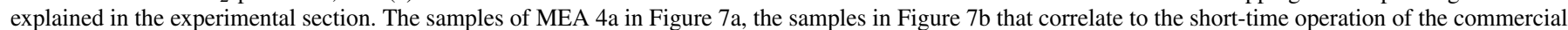

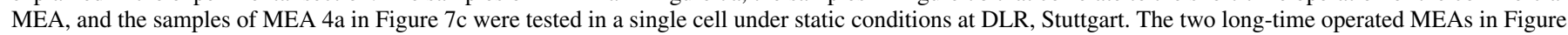
$7 \mathrm{~b}$ were tested in a stack under dynamic conditions at ZSW, Ulm. 


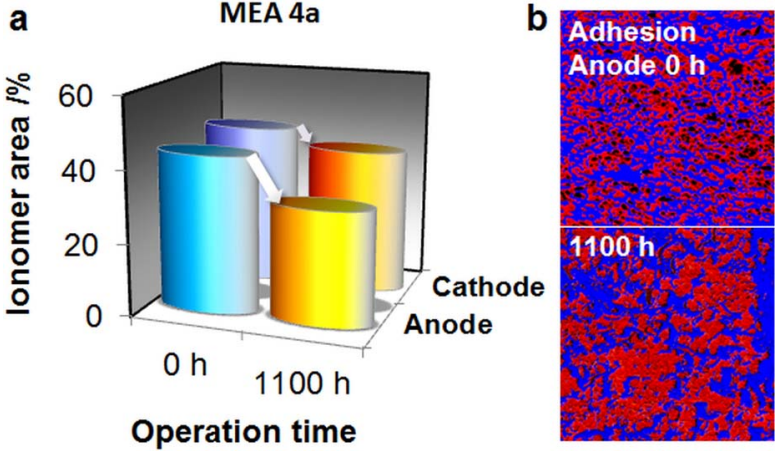

Figure 8. (a) Decrease of total ionomer area with operation time derived from adhesion mappings at MEA 4a cross-sections of anode and cathode, measured with AFM at 50\% RH, and (b) adhesion force mappings of MEA 4a anode with the high-adhesive area marked in blue. The MEA was tested in a single cell under static conditions at DLR, Stuttgart.

conductive area, indicates a higher loss of ionomer at the anode, similar to the above results with IR spectroscopy. The ionomer fraction can also be identified with adhesion mappings. It has been reported that in adhesion mappings recorded with material-sensitive AFM, the ionomer exhibits a higher adhesion to the AFM tip than $\mathrm{Pt} / \mathrm{C}$ agglomerates. ${ }^{13}$ In Figure $8 \mathrm{a}$, the area fraction with high adhesion according to ionomer is given. Similar to the decrease of non-conductive area given in Figure 7c the high-adhesion area decreased in a similar way with operation time from roughly $40 \%$ to $30 \%$, slightly more at the anode. In conclusion, the total ionomer fraction at both electrodes decreased with operation time. In Figure 8b, adhesion force mappings of the pristine and $1100 \mathrm{~h}$-operated electrodes with the ionomer fraction marked in blue (Figure 8b) show the corresponding ionomer fractions; a coarser adhesion force structure is visible after $1100 \mathrm{~h}$, a clear evidence for operation-induced ionomer agglomeration.

Potassium analysis.-The potassium content of the electrodes after ion exchange with protons is another measure for the total ionomer content comprising ionomer films and agglomerates. In Figure 9, the result of EDX analysis of the $\mathrm{K}$ content after ion exchange with protons at the MEA 4a anode is shown. The linear decrease of $\mathrm{K}$ content with operation time indicates a steady loss of protons $/ \mathrm{SO}_{3} \mathrm{H}$ groups and therefore a steady loss of ionomer with operation time in agreement with the previous results.

In conclusion, all experiments that determine the total amount of ionomer in the electrode revealed an operation-induced loss of ionomer in both electrodes. The decrease of the normalized $\mathrm{SO}_{3} \mathrm{H}$ intensity further indicates a preferred loss of sulfonic acid terminated side chains to main chains and clearly proofs degradation. Although a flow of ionomer out of the electrodes and merging with the membrane cannot be completely excluded (see discussion below), it is unlikely to

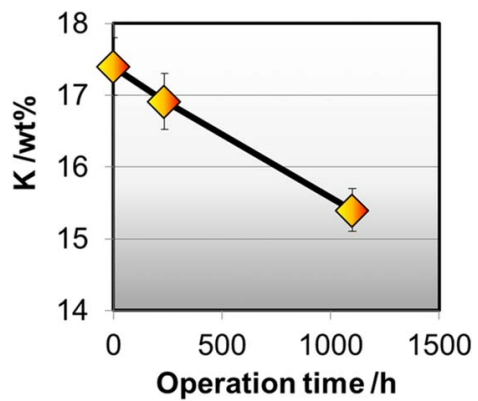

Figure 9. Dependence of K-content on operation time at the anode of MEA $4 \mathrm{a}$, derived by EDX analysis after ion exchange. The MEA was tested in a single cell under static conditions at DLR, Stuttgart. be a significant and dominant effect. Therefore the total ionomer loss in the electrodes is predominantly caused by chemical ionomer degradation. The reduced swelling of the thin ionomer films around $\mathrm{Pt} / \mathrm{C}$ agglomerates also indicates ionomer thinning by degradation. During operation, additionally a redistribution of the total ionomer fraction within the electrodes occurred. In the following section, an analysis of the ionomer agglomerate cluster size and distribution depending on operation time and position within the MEA time is presented.

Redistribution of ionomer within the catalytic layers. - The total ionomer area in the electrodes is determined strongly by the bigger ionomer agglomerates. However, the ionomer degradation affects only the surface of the agglomerates. Therefore, the total decrease in ionomer area is expected to be smaller than that of the thin ionomer films around $\mathrm{Pt} / \mathrm{C}$ agglomerates. In addition to the decrease of total ionomer content by fuel cell operation, a redistribution of the ionomer could be observed. In Figure 10, the adhesion images of a pristine (Figure 10a) and 1100 h-operated (Figure 10b) cross-section of MEA $4 \mathrm{~b}$ are given. The ionomer appears bright in the adhesion images. After $1100 \mathrm{~h}$ of operation, a significant increase of the number of large bright agglomerates is obvious; the average size of the ionomer agglomerates with operation time depended on the position in the MEA, demonstrated at the example of MEA 4c (Figures 10c) by comparison of 3 different positions: (i) within the anode at hydrogen inlet, (ii) at center, and (iii) at hydrogen outlet. The largest agglomerates were observed at the MEA center as given in Figures 10a and 10b, respectively. In Figures 10d and 10e, the dependence of agglomerate size on operation time is compared for the low-EW SSC-Aquivion D79-20BS in MEA 4a and for the high-EW LSC Nafion-based MEA 0476.The tendency to flow was higher for the low-EW Aquivion D79-20BS ionomer $\left(790 \mathrm{~g} \cdot \mathrm{mol}^{-1}\right)$ with shorter side-chains than for Nafion with an equivalent weight of $1100 \mathrm{~g} \cdot \mathrm{mol}^{-1}$; a result that may be explained by the difference in water content. ${ }^{79-81}$ For Nafion (and most-likely also for Aquivion), more water results in shorter inter-chain relaxation times that leads to ionomer plasticization. For that reason, the expected higher water content in the low-EW ionomer favors ionomer flow. The higher stability of Nafion may also be influenced by geometric constrictions due to the longer side chains that additionally stabilize Nafion.

Influence of ionomer layer thickness on performance degradation.- - In Figure 11, the dependence of irreversible degradation rates ${ }^{70,82,83}$ of differently prepared Aquivion-based MEAs from the EU "IMPACT"-project on average ionomer film thickness is drawn. A linear slope is visible for both electrodes, a slight decrease from linearity occurres at the cathodes. The degradation rate for the Nafion-based MEA, included for comparison in Figure 11, is slightly larger than for Aquivion-based MEAs. This linear correlation is not fully understood; possible explanations will be discussed in the following.

The comparison of degradation rates with average thickness of the ionomer layers clearly indicates an advantage of thinner films for longer lifetimes. A comparable finding was reported by Young et al ${ }^{84}$ Higher degradation was observed for fuel cells with MEAs that had a higher ionomer loading of the electrodes. The authors explained their findings with the resulting higher Pt-ion mass transport out of the electrode into the membrane in case of higher ionomer loading with a higher total conductivity. Subsequently, Pt-catalyzed membrane degradation damages the cells. The observed advantage of thinner ionomer films for degradation shown in Figure 11 could have similar reasons. It may be supplemented by a difference in Pt dissolution which is, however, speculative. The current-depending oxygen permeation resistance of the ionomer films and the resulting voltage drop across the ionomer is larger for thicker films. Following the outcome of a brief calculation, one could speculate, that a larger potential drop may cause a larger or even complete platinum oxide reduction. A varying current may then lead to a more frequently occurring higher or even complete Pt oxide reduction before re-oxidation. Due to the place exchange of $\mathrm{Pt}$ with oxygen atoms, the resulting higher $\mathrm{Pt}$ 

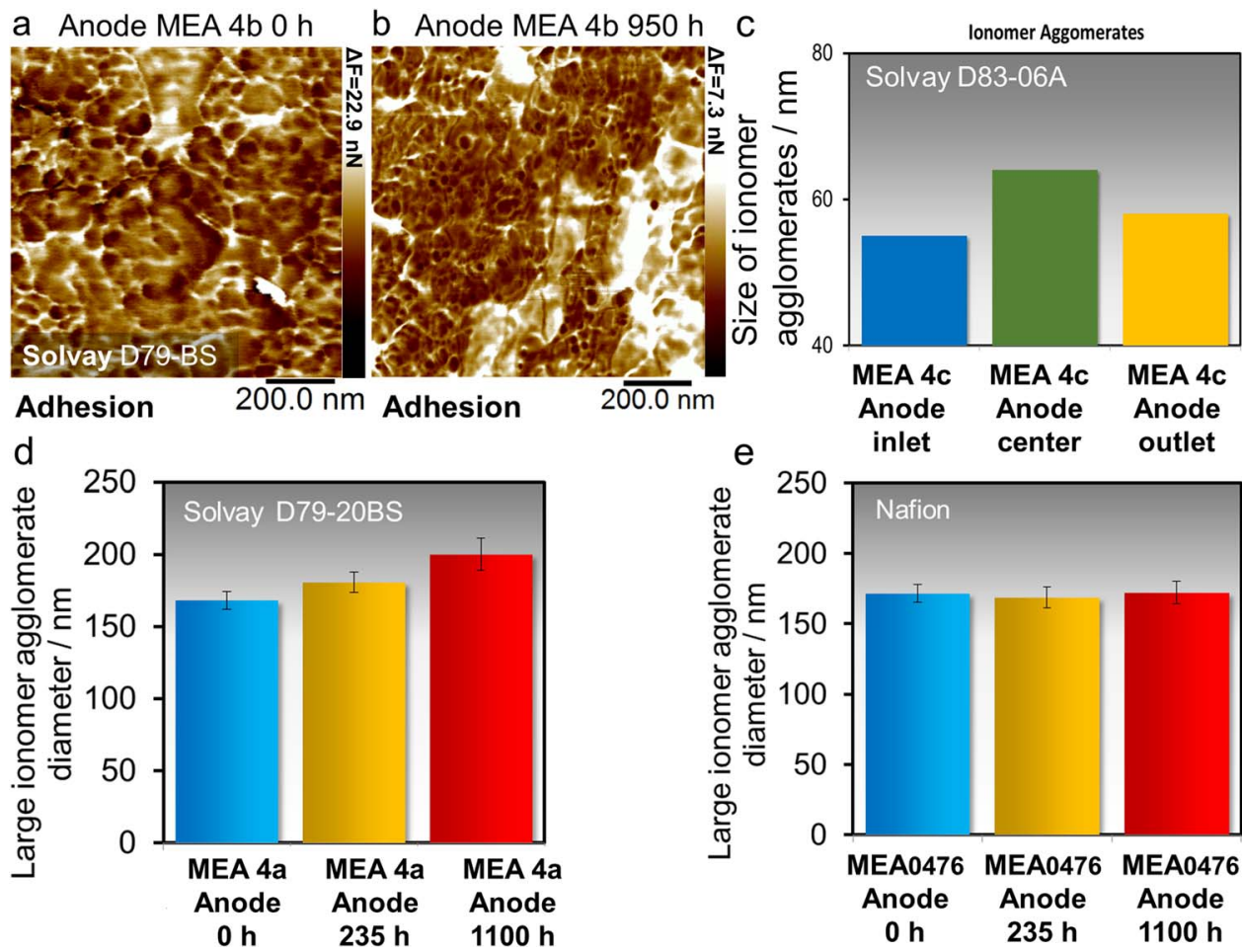

Figure 10. AFM adhesion images of MEA 4b, (a) pristine, (b) after $1100 \mathrm{~h}$ of operation, (c) size of ionomer agglomerates at different position of MEA $4 \mathrm{c}$ after $550 \mathrm{~h}$ operation, tested at DLR in a single cell at static conditions, (d) size of ionomer agglomerates after different operation time of anode of MEA 4a, and (e) of MEA 0476. MEA 4b and MEA4c were tested under dynamic conditions, the commercial reference MEA was tested under static conditions, all in a single cell at DLR, Stuttgart.

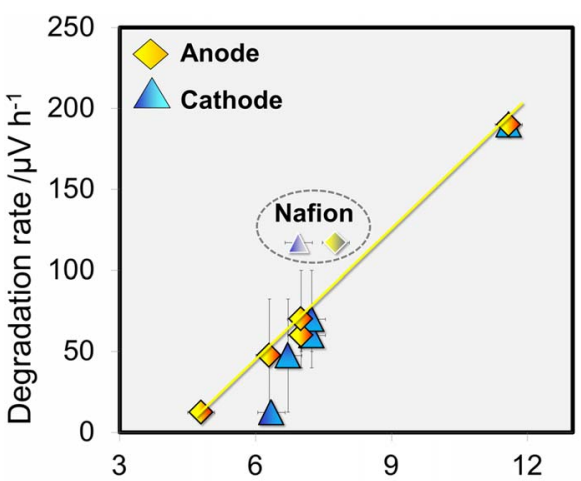

Cathode/anode ionomer layer thickness $/ \mathrm{nm}$

Figure 11. Dependence of irreversible degradation rates of differently prepared Aquivion-based MEAs on average ionomer film thickness for anode and cathode in new MEAs. All MEAs were tested in a single cell at DLR, Stuttgart, the commercial reference MEA and MEA 4a under static conditions, MEA 4b, MEA 4c, and MEA 5 under dynamic conditions.

mobility could increase Pt loss of the electrodes, further enhanced by a higher conductivity as proposed by Young et al. ${ }^{84}$ This relationship needs to be confirmed experimentally. A possible influence of radical scavengers introduced in the last three generations of membranes for mitigation of membrane decomposition does not affect the linear trend in the diagram. Therefore this indicates a dominant impact of electrode degradation in this case.

\section{Conclusions}

Cross-section of Aquivion-based fuel cell catalytic layers developed within the EU-project "IMPACT" were investigated. The change of ionomer content with operation time has been evaluated by means of material- and conductivity-sensitive AFM, infrared spectroscopy, and EDX. Two fractions of ionomer were discerned, bigger ionomer agglomerates and the thin ionomer films around $\mathrm{Pt} / \mathrm{C}$ agglomerates. For the conductivity and gas permeation properties of electrodes the latter are of major importance. A general loss of total ionomer fraction with operation time was observed with all analysis methods and to a large extent was assigned to ionomer degradation. In addition to the total ionomer loss, a redistribution of ionomer with operation time resulting in a growth of bigger ionomer agglomerates was found. The amount of agglomeration was dependent on the sample position within the MEA and the equivalent ionomer weight; it was found to be higher for the lower equivalent weight.

For the thin ionomer films in electrodes that are important for the ionic conductivity and the gas permeation properties, a combined loss of total film thickness and significantly reduced ionomer swelling was observed after $1100 \mathrm{~h}$ of operation and assigned to ionomer degradation. The distribution of ionomer films around $\mathrm{Pt} / \mathrm{C}$ agglomerates revealed that they fall within the frame of ultrathin films, a large fraction measured below $10 \mathrm{~nm}$. For such films a predominant layered structure is expected from modelling and recent experiments and could be confirmed by a linear swelling of the ionomer films with humidity. Moreover, a linear rise of irreversible degradation rate with ionomer film thickness was found and possible reasons were discussed.

\section{Acknowledgments}

The authors thank Dr. Jürgen Kraut for the SEM analysis. The research leading to these results received funding from the European Union's Seventh Framework Programme (FP7/2007-2013) for the Fuel Cells and Hydrogen Joint Technology Initiative under grant agreement $n^{\circ} 303452$, "IMPACT - Improved Lifetime of 
Automotive Application Fuel Cells with ultra-low Pt-loading", and grant agreement ${ }^{\circ}$ 621237, "INSIDE- In-situ Diagnostics in Water Electrolyzers".

\section{ORCID}

K. A. Friedrich (1) https://orcid.org/0000-0002-2968-5029

R. Hiesgen (D) https://orcid.org/0000-0002-0246-4509

\section{References}

1. T. Yoshida and K. Kojima, Interface Mag., 24, 45 (2015).

2. L. Bertuccioli, A. Chan, D. Hart, F. Lehner, B. Madden, and E. Standen, Development of Water Electrolysis in the European Union, Final Report, Fuel Cells and Hydrogen Joint Undertaking (ed.), (2014).

3. J. McBreen, J. Electrochem. Soc., 132, 1112 (1985).

4. W.-Y. Tu, W.-J. Liu, C.-S. Cha, and B.-L. Wu, Electrochimica Acta, 43, 3731 (1998)

5. W.-J. Liu, B.-L. Wu, and C.-S. Cha, J. Electroanal. Chem., 476, 101 (1999).

6. M. K. Debe, S. M. Hendricks, G. D. Vernstrom, M. Meyers, M. Brostrom, M. Stephens, Q. Chan, J. Willey, M. Hamden, C. K. Mittelsteadt, C. B. Capuano, K. E. Ayers, and E. B. Anderson, J. Electrochem. Soc., 159, K165 (2012).

7. M. K. Debe, Nature, 486, 43 (2012).

8. F. A. de Bruijn, V. A. T. Dam, and G. J. M. Janssen, Fuel Cells, 8, 3 (2008).

9. K.-D. Kreuer and G. Portale, Adv. Funct. Mater, 23, 5390 (2013).

10. D. Damasceno Borges, G. Gebel, A. A. Franco, K. Malek, and S. Mossa, J. Phys. Chem. C, 119, 1201 (2015).

11. R. Hiesgen, T. Morawietz, M. Handl, M. Corasaniti, and K. A. Friedrich, Electrochimica Acta, 162, 86 (2015)

12. R. Hiesgen, S. Helmly, T. Morawietz, X.-Z. Yuan, H. Wang, and K. A. Friedrich, Electrochimica Acta, 110, 292 (2013).

13. T. Morawietz, M. Handl, C. Oldani, K. A. Friedrich, and R. Hiesgen, ACS Appl. Mater. Interfaces, 8, 27044 (2016)

14. K. A. Mauritz and R. B. Moore, Chem. Rev., 104, 4535 (2004).

15. A. Kusoglu and A. Z. Weber, Chem. Rev., 117, 987 (2017).

16. G. Alberti, R. Narducci, and M. Sganappa, J. Power Sources, 178, 575 (2008).

17. R. Hiesgen, S. Helmly, I. Galm, T. Morawietz, M. Handl, and K. A. Friedrich Membranes, 2, 783 (2012)

18. R. Hiesgen, T. Morawietz, M. Handl, M. Corasaniti, and K. A. Friedrich, J. Elec trochem. Soc., 161, F1214 (2014).

19. M. Lopez-Haro, L. Guetaz, T. Printemps, A. Morin, S. Escribano, P.-H. Jouneau, P. Bayle-Guillemaud, F. Chandezon, and G. Gebel, Nat. Commun., 5, 5229 (2014).

20. G. De Moor, C. Bas, N. Charvin, J. Dillet, G. Maranzana, O. Lottin, N. Caque, E. Rossinot, and L. Flandin, Int. J. Hydrog. Energy, 41, 483 (2016).

21. C. Chen and T. F. Fuller, Polym. Degrad. Stab., 94, 1436 (2009).

22. V. A. Sethuraman, J. W. Weidner, A. T. Haug, and L. V. Protsailo, J. Electrochem. Soc., 155, B119 (2008).

23. W. Bi, Q. Sun, Y. Deng, and T. F. Fuller, Electrochimica Acta, 54, 1826 (2009).

24. O. Antoine and R. Durand, J. Appl. Electrochem., 30, 839 (2000).

25. S. Chen, H. A. Gasteiger, K. Hayakawa, T. Tada, and Y. Shao-Horn, J. Electrochem. Soc., 157, A82 (2010)

26. N. Ramaswamy, N. Hakim, and S. Mukerjee, Electrochimica Acta, 53, 3279 (2008).

27. S. Mu, C. Xu, Q. Yuan, F. Xu, and P. Zhao, J. Appl. Polym. Sci., 129, 1586 (2013)

28. K. Chan and M. Eikerling, J. Electrochem. Soc., 158, B18 (2011)

29. S. Helmly, B. Ohnmacht, P. Gazdzicki, R. Hiesgen, Erich Guelzow, and K. A. Friedrich, J. Electrochem. Soc., 161, F1416 (2014).

30. H. J. H. Fenton, J. Chem. Soc. Trans, 65, 899 (1894).

31. F. D. Coms, ECS Trans., 16(2), 235 (2008).

32. C. D’Urso, C. Oldani, V. Baglio, L. Merlo, and A. S. Aricò, Int. J. Hydrog. Energy, 42, 27987 (2017)

33. M. Breitwieser, T. Bayer, A. Büchler, Ro. Zengerle, S. M. Lyth, and S. Thiele, J. Power Sources, 351, 145 (2017)

34. C. D’Urso, C. Oldani, V. Baglio, L. Merlo, and A. S. Aricò, J. Power Sources, 301, 317 (2016).

35. H. Iden and A. Ohma, J. Electroanal. Chem., 693, 34 (2013).

36. S. Holdcroft, Chem. Mater, 26, 381 (2014).

37. K. L. More, R. Borup, and K. S. Reeves, ECS Trans., 3, 717 (2006).

38. R. Borup et al., Chem. Rev., 107, 3904 (2007).

39. D. Paul, A. Fraser, J. Pearce, and K. Karan, ECS Trans., 41, 1, 1393 (2011).

40. D. K. Paul, A. Fraser, and K. Karan, Electrochem. Commun., 13, 774 (2011)

41. M. A. Modestino, D. K. Paul, S. Dishari, S. A. Petrina, F. I. Allen, M. A. Hickner, K. Karan, R. A. Segalman, and A. Z. Weber, Macromolecules, 46, 867 (2013).
42. D. K. Paul, K. Karan, A. Docoslis, J. B. Giorgi, and J. Pearce, Macromolecules, 46, $3461(2013)$

43. D. K. Paul and K. Karan, J. Phys. Chem. C, 118, 1828 (2014).

44. H. K. Shim, D. K. Paul, and K. Karan, Macromolecules, 48, 8394 (2015).

45. K. Karan, Curr. Opin. Electrochem., 5, 27 (2017).

46. H. K. Shim, D. K. Paul, and K. Karan, Macromolecules, 48, 8394 (2015)

47. D. Damasceno Borges, G. Gebel, A. A. Franco, K. Malek, and S. Mossa, J. Phys. Chem. C, 119, 1201 (2014)

48. D. Damasceno Borges, A. A. Franco, K. Malek, G. Gebel, and S. Mossa, ACS Nano, 7, 6767 (2013).

49. Q. Berrod, S. Lyonnard, A. Guillermo, J. Ollivier, B. Frick, A. Manseri, B. Améduri, and Gérard Gébel, Macromolecules, 48, 6166 (2015).

50. J.-H. Park, S.-D. Yima, T. Kima, S.-H. Parka, Y.-G. Yoona, G.-G. Parka, T.-H. Yanga, and E.-D. Park, Electrochimica Acta, 83, 294 (2012).

51. F. Mack, M. Klages, J. Scholta, L. Jörissen, T. Morawietz, R. Hiesgen, D. Kramer, and R. Zeis, J. Power Sources, 255, 431 (2014).

52. V. Berejnov, D. Susac, J. Stumper, and A. P. Hitchcock, ECS Trans., 50, 2, 361 (2013).

53. A. P. Hitchcock, V. Berejnov J, V. Lee, M. West, V. Colbow, M. Dutta, and S. Wessel, Power Sources, 266, 66 (2014).

54. V. Lee, V. Berejnov, M. West, S. Kundu, D. Susac, J. Stumper, R. T. Atanasoski, M. Debe, and A. P. Hitchcock, J. Power Sources, 263, 163 (2014).

55. S. Takahashi, J. Shimanuki, T. Mashio, A. Ohma, H. Tohma, A. Ishiharac, Y. Itoc, Y. Nishinod, and A. Miyazawa, Electrochimica Acta, 224, 178 (2017).

56. R. Hiesgen, T. Morawietz, M. Handl, and K. A. Friedrich, MRS Proc., 1774, 19 (2015).

57. S. Helmly, R. Hiesgen, T. Morawietz, X.-Z. Yuan, H. Wang, and K. A. Friedrich, $J$. Electrochem. Soc., 160, F687 (2013).

58. M. Schulze and C. Christenn, Appl. Surf. Sci., 252, 148 (2005)

59. J. M. Rheaume, B. Müller, and M. Schulze, J. Power Sources, 76, 60 (1998).

60. D. Susac, V. Berejnov, A. P. Hitchcock, and J. Stumper, ECS Trans., 41(1), 629 (2011).

61. V. Lee, D. Susac, S. Kundu, V. Berejnov, R. T. Atanasoski, A. P. Hitchcock, and J. Stumper, ECS Trans., 58, 473 (2013).

62. D. Susac, V. Berejnov, A. P. Hitchcock, and J. Stumper, ECS Trans., 50, 2, 405 (2013).

63. S. C. DeCaluwe and J. A. Dura, ECS Trans., 80, 8, 619 (2017).

64. D. R. P. Morris, S. P. Liu, D. Villegas Gonzalez, and J. T. Gostick, ACS Appl. Mater. Interfaces, 6, 18609 (2014).

65. C.-N. Sun, K. L. More, G. M. Veith, and T. A. Zawodzinski, J. Electrochem. Soc., 160, F1000 (2013).

66. A. P. Young, J. Stumper, and E. Gyenge, J. Electrochem. Soc., 156, B913 (2009).

67. S. H. Ahn et al., Int. J. Hydrog. Energy, 38, 9826 (2013).

68. G. Tsotridis et al., EU harmonised test protocols for PEMFCMEA testing in single cell configuration for automotive applications., Publications Office, Luxembourg, (2015) http://bookshop.europa.eu/uri?target=EUB:NOTICE:LDNA27632:EN:HTML

69. (2016) http://stacktest.zsw-bw.de/media-centre.html.

70. P. Gazdzicki, J. Mitzel, D. Garcia Sanchez, M. Schulze, and K. A. Friedrich, J. Power Sources, 327, 86 (2016).

71. R. Hiesgen, E. Aleksandrova, G. Meichsner, I. Wehl, E. Roduner, and K. A. Friedrich, Electrochimica Acta, 55, 423 (2009)

72. M. Watanabe, H. Uchida, Y. Seki, M. Emori, and P. Stonehart, J. Electrochem. Soc. 143, 3847 (1996).

73. M. Falk, Can. J. Chem., 58, 1495 (1980).

74. M. H. Litt, Polym. Prepr, 38, 40 (1997).

75. F. Ferdeghini, Q. Berrod, J-M. Zanotti, P. Judeinstein, V. G. Sakai, O. Czakkel, P. Fouquet, and D. Constantin, Nanoscale, 9, 1901 (2017).

76. T. Muzaffar, T. Kadyk, and M. Eikerling, Electrochimica Acta, 245, 1048 (2017).

77. A. Kongkanand and M. F. Mathias, J. Phys. Chem. Lett., 7, 1127 (2016).

78. M. Eikerling and A. A. Kulikovsky, Polymer electrolyte fuel cells: Physical Principles of Materials and Operation, p. 541, CRC Press, Taylor \& Francis Group, Boca Raton (2015).

79. K. A. Page, B. W. Rowe, K. A. Masser, and A. Faraone, J. Polym. Sci. Part B Polym Phys., 52, 624 (2014).

80. M. B. Satterfield and J. B. Benziger, J. Polym. Sci. Part B Polym. Phys., 47, 11 (2009).

81. J. Benziger et al., in Fuel Cells and Hydrogen Storage, 85, F. A. Armstrong, P. Dayl, X. Duan, L. H. Gade, K. R. Poeppelmeier, G. Parkin, and J.-P. Sauvage, Editors, Structure and Bonding Series, D. M. P. Mingos, Series Editor, Springer Heidelberg (2011).

82. P. Gazdzicki, M. Schulze, and K. A. Friedrich, Meet. Abstr, MA2016-01, 111 (2016).

83. F. Wang, D. Yang, B. Li, H. Zhang, C. Hao, F. Chang, and J. Maa, Int. J. Hydrog. Energy, 39, 14441 (2014).

84. A. P. Young, J. Stumper, S. Knights, and E. Gyenge, J. Electrochem. Soc., 157, B425 (2010) 